\title{
EXPANSÃO DO ENSINO SUPERIOR: NOTAS SOBRE SEUS LIMITES E POSSIBILIDADES SOCIAIS
}

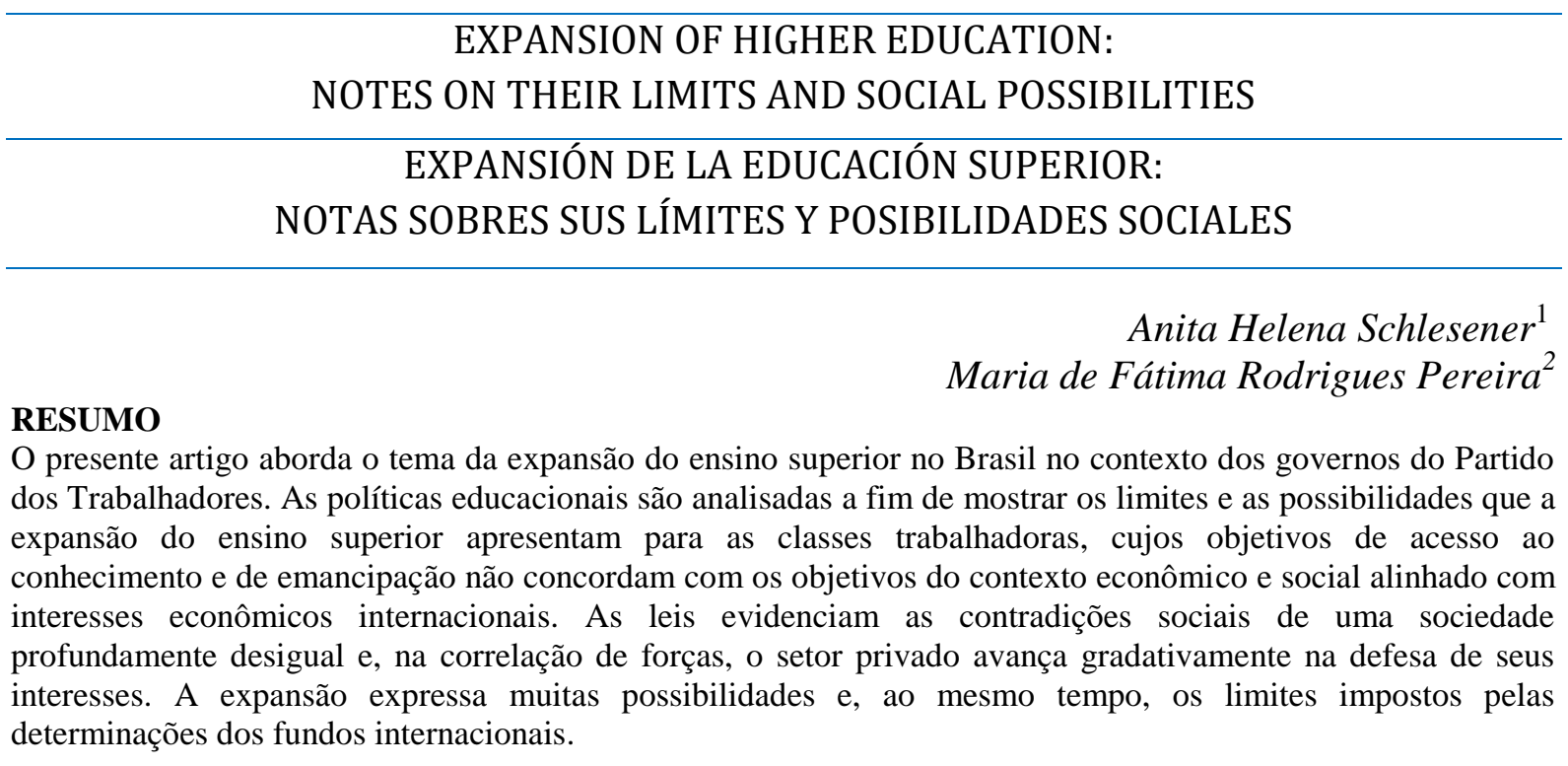

PALAVRAS-CHAVE: Ensino superior. Gestão democrática. Burocracia. Educação.

\begin{abstract}
This article addresses the subject of the expansion of higher education in Brazil in the context of the governments of the Workers' Party. Educational policies are analyzed in order to show the limits and the possibilities that the expansion of college education presents to the working classes, whose objectives of access to knowledge and emancipation do not agree with the objectives of the economic and social context aligned with international economic interests The laws highlight the social contradictions of a deeply unequal society and, in the correlation of forces, the private sector is gradually advancing in defense of its interests. The expansion expresses many possibilities and, at the same time, the limits imposed by the determinations of international funds.
\end{abstract}

KEYWORDS: College education. Democratic management. Bureaucracy. Education.

\section{RESUMEN}

El presente artículo aborda el tema de la expansión de la educación superior en Brasil en el contexto de los gobiernos del Partido de los Trabajadores. Las políticas educacionales son analizadas con el fin de mostrar los límites y las posibilidades de que la expansión de la educación superior tiene para las clases trabajadoras, cuyos objetivos de acceso al conocimiento y la emancipación no están de acuerdo con los objetivos del contexto económico y social, en consonancia con los intereses económicos internacionales. Las leyes evidencian las contradicciones sociales de una sociedad profundamente desigual y, en la correlación de fuerzas, el sector privado avanza gradualmente en la defensa de sus intereses. La expansión expresa muchas posibilidades y, a la vez, los límites que imponen las determinaciones de los fondos internacionales.

PALABRAS CLAVE: Educación superior. Gestión democrática. Burocracia. Educación.

\footnotetext{
${ }^{1}$ Professora de Filosofia Política (aposentada) da UFPR; Professora em Educação da Universidade Tuiuti do Paraná. E-mail: anita.helena@ libero.it

${ }^{2}$ Professora do Mestrado e Doutorado em educação da Universidade Tuiuti do Paraná. E-mail:

maria.pereira@utp.br
}

Submetido em: 30/11/2016 - Aceito em: 13/12/2016

(C) Rev. Inter. Educ. Sup.

\begin{tabular}{l|l|l|} 
& Campinas, SP & v.2
\end{tabular}

\begin{tabular}{l|l} 
n.3 & p.518-531
\end{tabular}

set./dez. 2016 


\section{Introdução}

Tratar do ensino superior e de sua expansão a partir da década de 1990 supõe uma questão inicial: por que, somente depois de quase um século da existência da Universidade brasileira, se coloca a necessidade de sua expansão? Como contextualizar o discurso que defende esta necessidade como própria das classes populares? A função da Universidade não é a função específica de formar as classes dirigentes? Por que esta necessidade se coloca no Brasil a partir da década de 1990 ?

Para explicitar estas questões precisamos retomar a crise do capitalismo do final da década de 1960, antecipada pela luta contra o imperialismo anunciada nos movimentos de maio de 1968, nas lutas feministas, raciais e na situação dos imigrantes. Ao longo da década de 1970 propagou-se a ideia de que se tratava de uma crise do Estado, discurso que rearticulou a política internacional em torno da solução necessária: novas políticas de exclusão social com o fim de direitos arduamente conquistados, "ajustes estruturais das economias dependentes e a reestruturação produtiva" como as duas faces do neocolonialismo (BRAGA, 2000, p. 56).

As grandes questões enfrentadas nesta nova fase de internacionalização do capital vinculam-se ao processo de flexibilização do trabalho, sua fragmentação e terceirização, movimento que se caracteriza tanto pela diminuição do proletariado fabril, fruto das novas formas de produção geradas a partir da inserção de novas tecnologias, quanto pela ampliação do setor de serviços, nas variadas formas de trabalho precarizado e terceirizado (ANTUNES; ALVES, 2004). Este processo, que gera um aumento do desemprego em todas as áreas, vem acompanhado da reestruturação do Estado e da privatização de setores do serviço público voltados a garantir direitos sociais. O Brasil insere-se no processo de mundialização do capital em relação de dependência econômica, iniciada com o processo de industrialização e acentuada principalmente no período da ditadura militar, tornando-nos sempre mais dependentes dos fundos financeiros internacionais.

A partir da reestruturação das relações de trabalho que se inserem no contexto político do neoliberalismo, modifica-se o significado de classe trabalhadora, que envolve todos os que vivem do trabalho, nas suas variadas formas:

\footnotetext{
A classe trabalhadora, hoje, também incorpora o proletariado rural, que vende a sua força de trabalho para o capital, de que são exemplos os assalariados das regiões agroindustriais, e incorpora também o proletariado precarizado, o proletariado moderno, fabril e de serviços, part-time, que se caracteriza pelo vínculo de trabalho temporário, pelo trabalho precarizado, em expansão na totalidade do mundo produtivo. Inclui, ainda, em nosso entendimento, a totalidade dos trabalhadores desempregados (ANTUNES; ALVES, 2004, p. 342).
}

Em linhas gerais, fazem parte da classe trabalhadora todos os que "vivem da venda de sua força de trabalho" (ANTUNES; ALVES, 2004, p. 336), sendo inseridos no mundo da produção e tendo que se adaptar a suas mudanças, conforme se reestrutura o processo

\begin{tabular}{l|l|l|l|l|l|l} 
(C) Rev. Inter. Educ. Sup. & Campinas, SP & v.2 & n.3 & p.518-531 & set./dez. 2016 & ISSN 2446-9424
\end{tabular}


produtivo. No Brasil esta reestruturação se determina pelas relações de dependência em relação ao capital internacional e pelas políticas públicas que, muitas vezes, resultam de uma correlação de forças internas entre os interesses populares e os interesses da classe dominante.

A partir deste contexto, a necessidade de preparar mão-de-obra para as novas profissões que se abrem no mercado e dar sustentação às classes trabalhadoras para sua adaptação e inserção nas mudanças no processo produtivo, tem-se a expansão do ensino superior e sua mudança estrutural a fim de abrir a possibilidade de acesso e de formação nesta área de ensino. Trata-se de uma expansão que responde a interesses do capital que, por meio das instituições financeiras internacionais, incentiva o processo de massificação do ensino, independentemente de sua qualidade.

O Movimento Docente procura conjugar estes dois extremos, qualidade e massificação, a fim de manter determinados parâmetros de produção do conhecimento. Tratase de um embate que tem como pano de fundo a defesa da educação pública ante um processo de privatização da educação que se expande em âmbito mundial. Como posicionarse ante as leis do mercado e as necessidades das classes trabalhadoras? Como defender e ampliar o ensino superior num contexto de expansão do ensino privado e como direcionar esse tipo de educação para a formação dos trabalhadores, necessária para o desenvolvimento do próprio capitalismo? Como os governos do PT enfrentaram as grandes questões sociais e políticas no que se refere ao ensino superior?

O grande problema que se coloca para a educação contemporânea dos trabalhadores é a articulação entre a cúpula e a base do sistema educacional brasileiro, visto que uma educação de qualidade do ensino superior, mesmo para as especialidades no campo da produção, implica uma formação de qualidade na educação básica, fator que exige uma formação continuada de professores e uma qualificação dos projetos político-pedagógicos dos Municípios que oferecem esta formação. A proposição de políticas públicas educacionais implica explicitar o conjunto de relações de força que auxiliam ou impedem reformas que se encaminham no sentido desta articulação e como as proposições que aparecem nas legislações muitas vezes não encontram respaldo para sua efetivação prática.

Estas duas questões foram articuladas a partir dos governos do Partido dos Trabalhadores: houve uma expansão do ensino superior, tanto das Universidades Públicas quanto com a implantação de Institutos Federais em todo o território brasileiro. Ao lado da reforma universitária, os programas de Cotas e de reserva de vagas a alunos da rede pública, aliados ao PROUNI e ao FIES, que são voltados a alunos do ensino superior privado, formaram um conjunto que abriu novas perspectivas de acesso ao ensino superior aos filhos das classes trabalhadoras. A este processo de expansão se vincula a reformulação dos cursos de pedagogia e a qualificação das licenciaturas, momentos importantes para a articulação com a educação básica.

A partir deste contexto, o presente artigo visa a refletir sobre as práticas que se efetivaram a partir das ações do Movimento Docente no debate sobre a gestão política da

\begin{tabular}{l|l|l|l|l|l|l} 
(C) Rev. Inter. Educ. Sup. & Campinas, SP & v.2 & n.3 & p.518-531 & set./dez. 2016 & ISSN 2446-9424 \\
\hline
\end{tabular}


educação no sentido de articular ensino superior e educação básica. Sabe-se que pouco se concretizou em termos de realização desta articulação, mas as políticas existem, a começar pela LDB 9394/96, os PNEs de 2001/2010 e 2014/2024, e a reforma universitária (REUNI). Algumas tentativas se efetivaram a partir de atuações implementadas no interior das Universidades públicas, como a renovação das licenciaturas, desdobrando-se em Projetos e Observatórios da Educação voltados à qualificação dos Projetos Político-Pedagógicos, ações que se estenderam a parcerias com Universidades Privadas.

A partir deste contexto, abordamos algumas políticas públicas implementadas nos governos do PT que visam a concretizar tanto a expansão universitária quanto sua articulação com a educação básica. Trata-se de uma abordagem introdutória, para os limites deste artigo, visto que o tema abrange um tempo de 13 anos de governo.

A abordagem segue explicitando a questão da gestão democrática burguesa e os limites que a dimensão ideológica que sedimenta a política orienta a expansão do ensino superior. Com breves observações sobre burocracia e gestão democrática, visto que este tema é muito amplo, tentamos esboçar os limites da expansão do ensino superior, mostrando que as possibilidades de emancipação se encontram em identificar e superar contradições que nos põe a sociedade capitalista.

\section{Notas Sobre a Expansão do Ensino Superior no Brasil a Partir dos Governos do Partido dos Trabalhadores}

Não pretendemos abordar questões referentes ao projeto social do Partido dos Trabalhadores, visto que este projeto se alterou ao longo das disputas políticas e das alianças realizadas para alcançar o poder. Os programas e políticas públicas encaminhados no curso dos governos visavam a enfrentar o problema da inclusão social de grande parcela da população brasileira que se encontrava em situação de miséria, à margem de qualquer direito que a Constituição de 1988 pretendia garantir. O projeto social nascido das bases organizativas dos trabalhadores em geral transformou-se na efetivação de algumas políticas de inclusão social que, ante a imensa desigualdade instaurada, conseguiram amenizar as injustiças, mas no seu conjunto, visavam a garantir o desenvolvimento do capital.

As políticas públicas educacionais, em geral, trazem a marca das ações reivindicatórias do Movimento docente no sentido de garantir direitos sociais e gerar a possibilidade de acesso a uma formação qualificada aos filhos das classes trabalhadoras; os interesses das classes populares de uma formação integral embatem-se com os interesses que visam a mera preparação para fins de empregabilidade. A correlação de forças, entretanto, não favoreceu aos movimentos que agiam a partir de objetivos de emancipação, como tentaremos mostrar a partir de alguns conteúdos retirados das políticas educacionais.

Partindo-se da LDB 9394/96, encontramos as seguintes finalidades da educação superior: I- estimular a criação cultural e o desenvolvimento do espírito científico e do

\begin{tabular}{l|l|l|l|l|l|l} 
(C) Rev. Inter. Educ. Sup. & Campinas, SP & v.2 & n.3 & p.518-531 & set./dez. 2016 & ISSN 2446-9424 \\
\hline
\end{tabular}


pensamento reflexivo; II - formar diplomados nas diferentes áreas de conhecimento, aptos para a inserção em setores profissionais e para a participação no desenvolvimento da sociedade brasileira, e colaborar na sua formação contínua; III - incentivar o trabalho de pesquisa e investigação científica, visando o desenvolvimento da ciência e da tecnologia e da criação e difusão da cultura, e, desse modo, desenvolver o entendimento do homem e do meio em que vive; IV - promover a divulgação de conhecimentos culturais, científicos e técnicos que constituem patrimônio da humanidade e comunicar o saber através do ensino, de publicações ou de outras formas de comunicação; V - suscitar o desejo permanente de aperfeiçoamento cultural e profissional e possibilitar a correspondente concretização, integrando os conhecimentos que vão sendo adquiridos numa estrutura intelectual sistematizadora do conhecimento de cada geração; VI - estimular o conhecimento dos problemas do mundo presente, em particular os nacionais e regionais, prestar serviços especializados à comunidade e estabelecer com esta uma relação de reciprocidade; VII promover a extensão, aberta à participação da população, visando à difusão das conquistas e benefícios resultantes da criação cultural e da pesquisa científica e tecnológica geradas na instituição.

Estes sete pontos alinhados indicam o caminho para uma formação integral que oriente todo o processo educativo, aliando o ensino, com a pesquisa e a extensão. As Universidades públicas têm se empenhado, ao longo dos anos, em concretizar esta relação, embora com grande dificuldade em implementar as ações relativas à extensão, ou seja, difundir seus resultados de modo a integrar Universidade e sociedade. Os objetivos exarados nas leis não se coadunam com o que os governos reservam para investir na educação.

A LDB 9394/96 foi sendo alterada no curso dos anos seguintes, em função de interesses políticos voltados à implementação do ideário neoliberal. O conteúdo original foi sendo alterado e o próprio significado de educação mudou conforme o novo projeto de sociabilidade assumido pelo governo. A educação, aos poucos, deixa de ser entendida como um direito de todos para ser apresentada como um serviço que pode ser adquirido no mercado. Trata-se, agora, de um investimento que não precisa ser do Estado, mas sim do próprio indivíduo interessado em melhorar sua qualidade de vida. Enquanto política que responde a interesses internacionais, a educação pode ser entendida como um caminho seguro para o controle social, na medida em que se aprofunda a desigualdade que, no seu extremo, é geradora de conflitos sociais.

Desta perspectiva, a expansão do ensino superior se apresenta como um projeto de inserção social a partir de qualificação em nível tecnológico, de graduação e de pósgraduação, de mão-de-obra para a recomposição da divisão social do trabalho, seja pela formação de trabalhadores para trabalhos mais complexos, seja pela difusão desta ordem que precisava ser consentida. Na correlação de forças, “estes princípios e políticas deles decorrentes se constituíram, na contramão, também, como possibilidade de pressão de professores e estudantes para o acesso ao ensino superior, destruição da monopolização do conhecimento pela burguesia e pela democratização do ensino superior" (LIMA, 2007, p. 127).

\begin{tabular}{l|l|l|l|l|l|l} 
(C) Rev. Inter. Educ. Sup. & Campinas, SP & v.2 & n.3 & p.518-531 & set./dez. 2016 & ISSN 2446-9424 \\
\hline
\end{tabular}


As políticas públicas de expansão do ensino superior apresentam-se ainda como tentativas de concretizar os compromissos assumidos no Plano Nacional de Educação PNE (2001-2010), que fixa metas neste sentido. De acordo com o MEC, as ações visavam a ampliar o número de instituições federais que, em 2002, se constituíam de 45 Universidades Federais e 148 campus/unidades. A primeira fase de expansão (2003-2007) "teve como principal meta interiorizar o ensino superior público federal", provendo as condições necessárias para o acesso e permanência do estudante (BRASIL, 2012, p. 9).

Esta ampliação, se considerada quantitativamente, apresenta-se como algo fenomenal, inovador, que abre a possibilidade de acesso ao ensino superior em grande escala, o que se confirma pela quantidade de vagas criadas que, em dez anos, duplicaram. Conforme fonte do INEP (2012), no "período 2010-2011, a matrícula cresceu 7,9\% na rede pública e 4,8\% na rede privada. As IES privadas têm uma participação $73,7 \%$ no total de matrículas de graduação". Estes dados nos mostram que apesar da expansão do ensino público, as instituições privadas têm uma participação maior nesta fatia da educação. Caberia, ainda, considerar a relação entre esta ampliação e a liberação de recursos públicos para as IES Federais e se os recursos liberados atendem às necessidades do ensino, pesquisa e extensão, análise que não faremos aqui.

Podemos acrescentar ao ensino público a criação dos novos Institutos Federais de Educação, mais de 600 unidades espalhadas pelo território nacional, que oferecem ensino superior, ensino médio e médio integrado, com objetivos de formação profissional e tecnológica. Pela sua organização interna e objetivos postos, os Institutos voltam-se prioritariamente para o ensino e a formação profissional, embora em algumas unidades os quadros de professores se organizem no sentido da pesquisa. Cabe entender como estas políticas se dirigem a efetivar objetivos dos fundos financeiros, ao controle formação profissional da população potencialmente voltada ao mercado de trabalho.

Para a efetivação das metas do PNE e a geração das condições de acesso e permanência do estudante, foi implementado pelo Decreto 6.096/2007 o Programa de Apoio a Planos de Reestruturação e Expansão das Universidades Federais (REUNI). Este Programa objetiva algumas mudanças internas de revisão da estrutura acadêmica e da composição curricular no sentido de redefinir a ocupação das vagas ociosas nas unidades existentes e abrir cursos noturnos. A grande novidade que nos interessa aqui é que este decreto propõe a articulação da graduação com os cursos de Pós-graduação e, ao mesmo tempo, da educação superior com a educação básica (BRASIL, 2012).

Estas duas fases: interiorização e reestruturação do sistema de ensino já existente, foram acompanhadas pela "fase de integração regional e internacional" com a criação de quatro universidades: duas regionais - Fronteira Sul (UFFS) e integração amazônica (UFOPa); duas internacionais - Integração Latino-Americana (Unila) e Integração Internacional da Lusofonia Afro-Brasileira (Unilab). O sistema continuou a ser ampliado, atingindo em 2010, 59 Universidades Federais e 274 campus/unidades. De 2011 a 2014 foram criados mais 47 campus, com tramitação de criação de mais quatro Universidades

\begin{tabular}{|l|l|l|l|l|l|l} 
(C) Rev. Inter. Educ. Sup. & Campinas, SP & v.2 & n.3 & p.518-531 & set./dez. 2016 & ISSN 2446-9424
\end{tabular}


regionais, duas no interior da Bahia, uma no Cariri (Ceará) e uma no interior do Pará (BRASIL, 2012).

Estas medidas possibilitaram ampliar em mais de $100 \%$ o número de vagas que, para serem destinadas às classes populares, foram coordenadas de modo a garantir o acesso por meio de políticas adicionais, como o ENEM, a regulamentação do acesso por meio da Lei de cotas, a reserva de vagas para alunos das escolas públicas, o Programa de Bolsa Permanência (PBP), o Programa Nacional de Assistência Estudantil (Pnes), o Programa Milton Santos de acesso ao Ensino Superior (Promisaes), entre outros.

Pode-se dizer que, no conjunto, alinhadas e articuladas, estas políticas poderiam, por si mesmas, promover uma grande mudança no sistema educacional superior. Na sua articulação, poderiam efetivar o que a LDB 9394/96 definiu, para o ensino superior, em primeiro plano, como três grandes e importantes objetivos: 1) a produção da cultura; 2) a formação do pensamento científico, 3) a formação do pensamento reflexivo. A realização destes objetivos daria ao conjunto da sociedade uma formação de profissionais nas diferentes áreas do conhecimento, bem como a produção de ciência tanto para atender as áreas sociais quanto para o desenvolvimento do capitalismo nacional. Poderia, ainda, reforçar uma das metas primordiais da educação universitária, que é a articulação entre ensino, pesquisa e extensão, que ficam claros no artigo 44 da LDB 9394/96.

Esta perspectiva, porém, passa a ser delimitada por outras políticas, como os Decretos 2.306/97 e 3.869/2001 que esclarecem a estrutura das instituições de ensino superior no país e sua hierarquização em ordem de importância e de funcionalidade. Estes decretos respondem a objetivos do Banco Mundial e da Unesco nas suas políticas para a América Latina, de modo que se hierarquizam Universidades, Centros Universitários, Faculdades e Escolas Isoladas, Institutos Superiores de Educação, conforme interesses de formação para o mercado.

Os institutos, por não terem a exigência da pesquisa e da formação dos docentes que ali trabalham em nível do stricto sensu, oferecem a custos de mercado a formação aos professores. Acrescente-se a diminuição do tempo de formação e a possibilidade de qualquer profissional, após ter feito a complementação para o magistério, estar habilitado ao trabalho do professor: temos configurado o barateamento da formação e remuneração do trabalho dessa categoria de trabalhadores.

Fica claro na comparação de decretos e leis, que não se pretende romper a hierarquia existente no plano do conhecimento, nem oferecer uma formação de qualidade, mas responder às determinações dos fundos financeiros de acordo com os interesses do capital, formando mão-de-obra para a reestruturação produtiva. Para Leher (1999, p. 19), a "redefinição dos sistemas educacionais está situada no bojo das reformas estruturais encaminhadas pelo Banco Mundial, guardando íntima relação com o par governabilidadesegurança”.

A ampliação quantitativa do acesso a partir de novas instituições e vagas é inegável, mas um dos complicadores que delimitaram este processo foi não levar em conta a

\begin{tabular}{l|l|l|l|l|l|l} 
(C) Rev. Inter. Educ. Sup. & Campinas, SP & v.2 & n.3 & p.518-531 & set./dez. 2016 & ISSN 2446-9424
\end{tabular}


precarização do trabalho docente com a constante redução dos incentivos à pesquisa concomitantemente a uma exigência de produção exacerbada, respondendo a interesses internacionais advindos dos fundos financiadores (Banco Mundial, FMI, UNESCO), dos quais continuamos a depender num contexto de governo neoliberal. Estamos sempre submetidos a políticas fiscais de vários tipos, todas visando restringir os investimentos em educação em todas as áreas. Nesse contexto, as políticas, em geral, precisam ser "negociadas" com representantes políticos que, embora eleitos com o voto popular, representam a si próprios ou a interesses do capital.

O que entra em conflito, neste conjunto, são os objetivos expostos nas políticas e a realidade de uma economia dependente de um país que se subjuga a determinações econômicas internacionais e de governos que assumem alianças neoliberais. As mudanças que ocorreram nos governos do PT não foram mudanças estruturais, mas, a partir de suas alianças políticas, as ações não puderam ser mais que paliativas.

Esta questão implica a posição ambígua dos governos do Partido dos Trabalhadores que, por um lado, pela sua origem e militância, representavam interesses populares e, por outro, a partir de suas alianças, assumiram práticas políticas que davam continuidade ao projeto neoliberal instaurado no governo anterior. Assim, a expansão do sistema federal e público do ensino superior foi concomitantemente acompanhado pelo incentivo ao ensino privado, acirrando as disputas por este mercado.

Ouro ponto a abordar é o da avaliação: as políticas de expansão são acompanhadas por políticas de avaliação que, no seu conjunto, ferem a autonomia universitária, tanto do ponto de vista didático quanto da própria produção científica; o Estado, seguindo uma política mundial de avaliação, institui políticas e sistemas de avaliação integrados, a tal ponto que autoriza que se fale num Estado Avaliador que promove uma homogeneização da educação. Nesta mesma direção deve ser entendida a extinção do Conselho Federal de Educação e a criação do Conselho Nacional de Educação no Governo FHC que se refletiu em maior poder do MEC e maior flexibilidade na criação dos critérios para a criação dos cursos de graduação.

Não estamos negando a importância de avaliações institucionais em todos os âmbitos de educação, o que se interroga são os métodos de avaliação destinados a responder a interesses que não são internos ao sistema de ensino e ao coletivo que se empenha na atividade educacional e de pesquisa. Avaliações meramente quantitativas com o objetivo de responder a interesses de financiamento internacional apenas atrapalham o andamento do processo educativo em geral.

As contradições se evidenciam na confrontação dos objetivos colocados nas políticas públicas e na sua efetiva aplicação, contradições geradas a partir de um discurso ideológico pretensamente emancipador e os reais interesses implícitos na elaboração das leis que visam efetivar tais políticas. A articulação entre a expansão do ensino superior público e o fortalecimento do setor privado ocorre num contexto de alianças neoliberais que minam qualquer ideia de emancipação política e cultural das classes trabalhadoras, que são o alvo

\begin{tabular}{l|c|c|c|c|c|c}
\hline (c) Rev. Inter. Educ. Sup. & Campinas, SP & v.2 & n.3 & p.518-531 & set./dez. 2016 & ISSN 2446-9424 \\
\hline
\end{tabular}


dessas políticas. A veiculação de conceitos abstratos e naturalizados como, por exemplo, a noção de gestão democrática, entendida meramente como adesão numérica de indivíduos em reuniões, permite implementar ações técnicas como se fossem políticas e adotar atitudes gerenciais como se fossem efetivamente democráticas, ou seja, frutos de decisão participativa. Sem que os próprios gestores se deem conta, as ideologias se materializam na prática cotidiana e, por não se refazer constantemente a análise conjuntural, perde-se a dimensão da dominação que se instaura por meio da ideologia.

Cabe perguntar sempre: a quem interessam estas políticas? Retomando Leher (1999, p. 19):

O caráter determinante das ideologias que informam a reforma educacional fica melhor evidenciado quando a investigação apresenta concretamente como as concepções ideológicas se materializam nas instituições. Para compreender as ideologias que transtornam a educação da América Latina, da África e de parte da Ásia, é preciso examinar os encaminhamentos do Banco Mundial, o ministério mundial da educação dos países periféricos.

Neste contexto, tomando as novas dimensões da ideologia articuladas com a nossa dependência econômica dos fundos internacionais, a expansão do ensino superior insere-se no âmbito dos interesses de controle econômico e social, a fim de manter um equilíbrio que permita diminuir as possibilidades de conflito.

\section{A Ideologia da Gestão Democrática Burguesa, a Burocracia e a Necessidade dos Trabalhadores}

Marx e Engels lembram-nos em A Ideologia Alemã que "os pensamentos da classe dominante são também, em todas as épocas, os pensamentos dominantes, ou seja, a classe que tem o poder material dominante numa dada sociedade é também a potência dominante espiritual” (MARX; ENGELS, 1974, p. 57). A gestão democrática sob os interesses da reprodução ampliada do capital converte-se em ideias e práticas do seu domínio, compõe-se como elemento de alienação, porque se na abstração cada indivíduo é um entre iguais, no mundo real "aparece na sua realidade desigual, como um instrumento em mãos de poderes que lhe são alheios e incontroláveis. Iguais no céu, profundamente desiguais na terra, e, dada essa antinomia, a igualdade celestial não faz mais que reproduzir e agigantar as desigualdades estruturais da segunda" (BORON, 2006, p. 309). Daqui decorre para o capital a exigência de afirmar a inclusão, a cidadania, a distribuição social que não se realiza.

Nunca se propagou tanto a ideia de que vivemos numa "sociedade do conhecimento", cuja expressão se encontra no acelerado desenvolvimento das novas tecnologias de produção e comunicação. Entretanto, nunca o conhecimento esteve tão concentrado em poucas mãos quanto nas últimas décadas, servindo para a concentração do poder e da riqueza mundiais.

Ora, esta condição encontra na burocracia, agora fortalecida pelos sistemas de informação e suas lógicas binárias presentes no ensino superior e básico, uma das pontas de

\begin{tabular}{l|l|l|l|l|l|l} 
(C) Rev. Inter. Educ. Sup. & Campinas, SP & v.2 & n.3 & p.518-531 & set./dez. 2016 & ISSN 2446-9424
\end{tabular}


lança para a manutenção das relações de produção do conhecimento e da educação, a finalidade de garantir a formação que interessa à extração de valor, hoje flexível e adaptativa.

A origem da burocracia encontra-se na divisão social do trabalho e, nesta perspectiva, o ensino superior é apresentado sob a ótica do economicismo, investimentos parcos para resultados imediatos, uma das formas de esconder e minimizar a subordinação escravizadora dos indivíduos à divisão do trabalho material e intelectual. A burocracia assume uma dimensão ideológica que se apresenta nas intenções que permeiam os discursos, voltadas ao bem de toda a sociedade, intenções que não se efetivam porque se reduzem a ações administrativas cuja eficácia é muito limitada. No entanto, a burocracia, assim como a "gestão democrática", são as bases da organização do Estado burguês e atuam como fortes formadores do senso comum, cujas expectativas são alimentadas, mas nunca ou precariamente realizadas.

Assim sendo, a burocracia estatal, no contexto neoliberal, concorre para a produção de conhecimento que amplie as possibilidades de extração de mais valia, fato que se apoia na expansão do ensino em cursos de inovação tecnológica, empreendedorismo e financiamentos de projetos de pesquisa que reforçam as condições de distribuição concentrada da riqueza e sua fruição. A burocracia administrativa que se estende nas mais variadas formas no contexto do capitalismo mundial, tanto em empresas quanto em partidos políticos e mesmo na estrutura sindical completam o processo de controle e administração das relações econômicas e sociais, cristalizando a separação entre dirigentes e dirigidos.

No ensino superior, não são poucos os protocolos, as plataformas, os formulários, prazos a serem cumpridos, determinações e condicionantes de editais de projetos a serem respondidos cujos pareceres se assemelham. Assim, projetos de pesquisa importantes, mas que não atendem às exigências técnicas, não são contemplados; trava-se aí também a luta de classes, a luta pela produção das explicações do mundo, as disputas pelo que se ensina e como se ensina.

Instala-se, consolida-se um ensino sem alma, desalentador, porque desprovido de sentido e significado real que se expande nas salas de aula, nas reuniões de colegiados, em Seminários e publicações que lotam as editoras e cujo descarte é anunciado; destroem-se forças produtivas para manter as relações de produção. Elaboram-se Projetos PolíticoPedagógicos, quando o tempo dos professores permite, mas sempre atendendo às normas e diretrizes ou aos prazos que se esgotam; alguém os elabora, o importante é tê-los, bem guardados para serem desengavetados com ar solene; afinal, foram fruto de diligência no cumprimento do poder delegado, uma prática que funciona "da mesma forma que o feiticismo mercantil [que] esconde as relações sociais sob o manto opaco da categoria comprador- vendedor, mediado pela mercadoria" (TRAGTEMBERG, 2012, p. 43).

A reprodução das relações sociais para ampliação da extração de mais valia encontra na estrutura burocrática seu instrumento, "é uma alavanca na realização da mais-valia e na sua redistribuição entre as diferentes frações da classe dominante" (TRAGTEMBERG, 2012, p.65). Os apontamentos sobre a expansão do ensino superior feitos já antes neste texto

\begin{tabular}{l|l|l|l|l|l|l} 
(C) Rev. Inter. Educ. Sup. & Campinas, SP & v.2 & n.3 & p.518-531 & set./dez. 2016 & ISSN 2446-9424 \\
\hline
\end{tabular}


ganham agora explicação em sua particularidade, em tempos de larga presença da racionalidade mercantil, burocratizada.

Para Tragtemberg (2012, p. 64),

\begin{abstract}
Weber aponta na burocracia um sem número de qualidades, tais como: precisão, rapidez, oficialidade, continuidade, descrição, uniformidade, rigorosa subordinação, impessoalidade no julgamento, eliminação do amor e do ódio e de todos os elementos racionais não passíveis de cálculo. A ação burocrática realiza para Weber a ação racional vinculada a fins. Em nível extremo, se corporifica na dominação burocrática- legal. Atua como reprodução do capitalismo, na medida em que a reação racional corporificada nas estruturas burocráticas permite a universalização do cálculo racional.
\end{abstract}

Neste sentido, constituindo-se expressão particular dessa gestão administrativa e burocratizada, há a considerar que todo o "funcionário moderno pretende sempre e habitualmente desfrutar de uma estima social específica, em comparação com os governados" (WEBER, 1982, p. 233). Uma relação de submissão e cumplicidade com o poder que, no ensino superior traduz-se, atualmente, pela nomeação de reitores dos Institutos sob intervenção do MEC, pela nomeação de secretários de educação pelos governos estaduais, das equipes das secretarias federais e equipes de conselheiros. Sua autonomia de reflexão e decisão é interpretada, frequentemente, como rebelião, suas dissidências castigadas com o isolamento. Por outro lado, também, a permanência no cargo não está garantida porque, em formações sociais nas quais as disputas sob visões e práticas políticas de mando das classes hegemônicas, o poder submete e determina. Todavia há que se levar em conta que a eleição entre os governados embate o rigor da subordinação hierárquica e abre caminho para a contradição, ainda que esta seja vista como prejuízo à eficácia institucional.

Estes níveis da burocracia repicam-se e preservam-se nas relações entre professores e alunos, tomando o lugar da efetiva garantia de apropriação e produção da cultura, da ciência, da arte, da filosofia, como exarado na LDB/96, enquanto mediação de leitura e produção da vida; no cotidiano do ensino cultuam-se os protocolos, os modelos informados por uma lógica formal alienante e conformadora ao estabelecido, as avaliações como estão estabelecidas em larga e pequena escala, valorizando o quantitativo, a descrição empírica, a superficialidade dos dados coletados e analisados com pressupostos formais. "Na defesa da escola enquanto instituição, leiga ou confessional, pública ou particular, há o desejo secreto de preservá-la das contradições e dos conflitos sociais em que se constitui como reflexo ou mecanismo de dissimulação [...]" (TRAGTEMBERG, 2012, p. 71). Há uma demora no ensino superior e básico para a formação necessária a uma vida ativa, emancipada.

Isso se deve em grande medida à presença de visões e práticas fetichistas. Atrás da burocracia que informa a expansão do ensino superior e suas relações com a educação básica se esconde a monocracia do mercado segundo a qual estudantes e professores se transformam em números de processos burocráticos, em que a ciência possível é a da ordem, o empobrecimento de formação que enfraquece as possibilidades de emancipação. Ao capital 
interessa esse ensino superior de homens e mulheres desamparados, descontextualizados, banalizados e impotentes, exércitos de reserva dos seus empreendimentos.

Mas, as mesmas relações de produção que dão espaço a este ensino superior, também engendram a possibilidade de sua crítica e superação. Isto também é feito e diz respeito ao ensino que interessa aos trabalhadores a quem cabe produzir a vida sob seus interesses. $\mathrm{Na}$ correlação das forças em presença, garantir o direito de formação integral e de emancipação depende do processo de organização política, ou seja, todo o processo formativo escolar pode ser modificado se as classes trabalhadoras lutarem efetivamente por seus interesses. A classe trabalhadora precisa da escola, condição de se instruir como condição de sua emancipação.

Não tem sido poucas as tentativas de controlar e minimizar esse poder burocrático, de imediato podem ser apontadas: a eleição e sanções até se chegar à revogabilidade dos funcionários, superação do departamento, criação de órgãos ao mesmo tempo de planejamento e execução, isonomia salarial e plano de carreiras. O aparato legal se sobrepõe e entrava o trabalho voltado para a integração e a renovação do sistema.

Deparamo-nos com conflitos interpessoais de trabalho, de informações guardadas a sete chaves, de disputas, autonomização de setores em relação a outros. Recorre-se a decisões colegiadas para garantir participação e legitimidade dos interesses políticos. Assiste-se a ensaios, tentativas de superação da especialidade e instalação do diálogo, da cooperação solidária.

Sabemos da urgência em mudar o ensino superior e a escola básica, intuímos sua necessidade e, embora reconhecendo seus limites, identificamos possibilidades efetivas no trabalho associado.

\section{Breves Conclusões}

O Brasil se insere na economia mundial num momento de completa financeirização do capital. Os governos do PT começaram no início deste processo mundial de reestruturação da economia, um dos motivos de suas contradições entre intenções e práticas possíveis a partir de suas alianças para exercer o poder. As profundas alterações que foram se produzindo na estrutura econômica até se chegar ao momento crucial da crise, que se estende e que se aprofunda, foram enfrentadas com políticas cada vez mais conservadoras. No plano internacional, a aliança com os países emergentes na fundação do BRICS parecia anunciar um caminho de relativa autonomia ou, ao menos, a possibilidade de uma política antiimperialista, como entendemos a atitude política e econômica dos países emergentes. A burguesia imperialista, aliada a grupos conservadores internos, romperam com a nossa incipiente democracia, abrindo-se agora o caminho para a definitiva privatização dos bens públicos ainda garantidos pelo Estado. 
Neste contexto, insere-se a nossa breve abordagem da expansão do ensino superior e sua articulação com a educação básica. Uma expansão que, pelo cotejamento de algumas políticas educacionais, evidencia uma riqueza de possibilidades e, ao mesmo tempo, os limites impostos pelas determinações dos fundos internacionais. O que tentamos evidenciar é que as leis, em alguns momentos, expressam uma intenção que não se efetiva na prática, por uma série de contradições que impossibilitam a sua efetivação. Um dos pontos observados pelo cotejamento das leis é que a expansão pode visar a emancipação teórica e política das classes trabalhadoras pelo acesso ao ensino; mas esta intenção está comprometida pela hierarquia que as leis estabelecem entre as várias instituições criadas e que, ao ser explicitada, esta hierarquia demonstra que os objetivos são a formação de mão-de-obra mais ou menos especializada para responder aos interesses do mercado do trabalho.

No conjunto de relações, as políticas públicas de expansão do ensino superior revelam-se como tentativas de concretizar os compromissos assumidos tanto com os agentes financeiros que ditam regras aos países que deles dependem, principalmente a América Latina, quanto aos objetivos de encontros internacionais como Jontien, objetivos que se repetem nas nossas legislações educacionais e que também se encontram implícitos nos PNEs.

Ainda procuramos esboçar como a burocracia e a ideologia obnubilam todo o processo de aplicação das políticas educacionais, ocorrendo um esvaziamento da questão política, substituída pela questão administrativa, como se esta fosse uma atividade neutra e voltada para o bem de toda a sociedade.

Também salientamos algumas ambiguidades do Partido dos Trabalhadores, cuja trajetória foi marcada por compromissos cada vez mais conservadores, afastando-se dos verdadeiros interesses das classes trabalhadoras. Esta ambiguidade foi fruto da necessidade de o partido se posicionar ante um quadro econômico internacional determinado e tentar implementar políticas de inclusão social. No fundo, a trajetória do PT expressa de modo claro as contradições de uma sociedade profundamente desigual e injusta, de grandes oligarquias internas que não abrem mão de seus lucros, aliadas aos grupos capitalistas internacionais cujos objetivos são a mera acumulação de capital, chegando aos limites da barbárie.

Esta breve exposição nos coloca questões que nos desafiam a entender a estrutura econômica para, a partir dela, explicitar as relações entre os conteúdos legais e a sua efetivação, principalmente porque a dimensão ideológica das políticas, ao ser explicitada, evidencia os interesses em jogo e as correlações de forças que caracterizam as relações de poder. 


\section{Referências}

ANTUNES, Ricardo; ALVES, Giovanni. As mutações no mundo do trabalho na era da mundialização do capital. Educ. Soc., Campinas, v. 25, n. 87, p. 335-351, maio/ago. 2004. Disponível em <http://www.cedes.unicamp.br>. Acesso em: 28 nov. 2016.

BORON, Atilio A. Filosofia política e crítica da sociedade burguesa: O legado teórico de Karl Marx. In: BORON, Atilio A (Org.). Filosofia política moderna de Hobbes a Marx. Buenos Aires: CLACSO; San Pablo: FFLCH - USP, 2006.

BRAGA, Ruy. Globalização ou neocolonialismo? O FMI e a armadilha do ajuste. Revista Outubro, n.4, 2000, p. 55-69. Disponível em: <http://outubrorevista.com.br/wpcontent/uploads/2015/02/Revista-Outubro-Edic\%CC\%A7a\%CC\%83o-4-Artigo-06.pdf>. Acesso em: 28 nov. 2016.

BRASIL, MEC. Análise sobre a expansão das universidades federais 2003 a 2012. Brasília: 2012. Disponível em: <https://drive.google.com/file/d/0B0ktk9ppgz3naz Qxd2RrWWtOdnM/view>. Acesso em: 28 nov. 2016.

BRASIL, MEC-INEP. Resultado do Censo da Educação Superior 2011. Brasília: 2012. Disponível em: 〈https://drive.google.com/file/d/0B0ktk9ppgz3neFRxMmdsMnNsaEk/view>. Acesso em: 28 nov. 2016.

LEHER, Roberto. Um novo Senhor da educação? A política educacional do Banco Mundial para a periferia do capitalismo. Revista Outubro, n.3, 1999, p. 19-30. Disponível em: <https://drive.google.com/file/d/0B0ktk9ppgz3nT0FrWDRPQXVCcDA/view>. Acesso em: 28 nov. 2016.

MARX, Karl; ENGELS, Friedrich. A Ideologia Alemã. Lisboa, Editorial Presença; Martins Fontes: Brasil, 1974.

TRAGTEMBERG, Mauricio. Educação e burocracia. São Paulo: Fundação Ed. Unesp, 2012.

WEBER, Max. Ensaios de sociologia. Rio de Janeiro: Zahar Editores, 1982. 